\title{
Estudo soroepidemiológico de leishmaniose em equinos na região de Araçatuba-SP, Brasil, área endêmica para leishmaniose visceral
}

\section{A seroepidemiological study of leishmaniasis in horses in the region from Araçatuba-SP, Brazil, an endemic area for visceral leishmaniasis}

\author{
Francisco Leydson Formiga FEITOSA ${ }^{1}$; Juliani LEAL ${ }^{2}$; Luiz Cláudio Nogueira MENDES ${ }^{1}$; Juliana \\ Regina PEIRÓ ${ }^{1}$; Sílvia Helena Venturoli PERRI ${ }^{1}$; Valéria Marçal Felix de LIMA $^{1}$; Mary MARCONDES \\ ${ }^{1}$ Faculdade de Medicina Veterinária da Universidade Estadual Paulista, Araçatuba-SP, Brasil \\ ${ }^{2}$ Médica Veterinária Autônoma
}

\begin{abstract}
Resumo
O presente estudo teve como objetivo pesquisar a presença de anticorpos anti-Leishmania sp. em equinos provenientes do município de Araçatuba-São Paulo, área endêmica para leishmaniose visceral canina e humana. Dos 466 equinos testados para a presença de IgG anti-Leishmania chagasi pelo método de ELISA, 68 (14,59\%) apresentaram sororeatividade, com títulos variando entre 0,324 e 0,813 . As amostras de soro dos equinos positivos por ELISA foram testadas também por imunocromatografia, e 19/466 (4,08\%) apresentaram resultado positivo. Os resultados obtidos no presente estudo indicaram que esta espécie animal está em contato e deve atrair flebotomíneos transmissores da doença, e salientam a necessidade de investigação mais acurada sobre o real papel dos equinos residentes em áreas endêmicas, de forma a auxiliar nas medidas de controle da doença.
\end{abstract}

Palavras-chave: L. chagasi. Leishmaniose cutânea. ELISA. rk39.

\begin{abstract}
The aim of the present study was to perform a leishmaniasis survey in horses from Araçatuba, São Paulo, an endemic area of Brazil. Of the 466 horses tested for the presence of anti-Leishmania chagasi titers by ELISA, 68 $(14.59 \%)$ were seropositive, with titers varying between 0.324 and 0.813 . ELISA positive samples were also tested by immunocromatography and 19/466 (4.08\%) were positive. The results of the present study indicated that equines are in contact and can attract phlebotomines, and highlight the necessity of a more accurate investigation on the role played by the horses living in endemic areas, in order to help to control the spread of the illness.
\end{abstract}

Keywords: L. chagasi. Cutaneous leishmaniasis. ELISA. rk39.

Até o presente momento, de todos os animais identificados como reservatórios da leishmaniose visceral (LV), o cão, do ponto de vista epidemiológico, é considerado o mais importante reservatório doméstico ${ }^{1}$. No entanto, equinos também podem ser infectados, quando vivem em áreas endêmicas ${ }^{2}$. Apesar de pouco frequentes, existem descrições de equinos infectados por Leishmania infantum, o agente etiológico da leishmaniose visceral na Europa ${ }^{3,4,5}$. Partindo-se da hipótese de que equinos podem se infectar com espécies do gênero Leishmania, o presente estudo teve como objetivo pesquisar a presença de anticorpos anti-
Leishmania sp. em equinos provenientes de área endêmica para leishmaniose visceral canina e humana.

De janeiro a dezembro de 2006 foram coletadas amostras de sangue de 466 equinos residentes no município de Araçatuba-São Paulo. A pesquisa de

Correspondência para:

Francisco Leydson Formiga Feitosa

Rua Clóvis Pestana, n. 793, Jardim Dona Amélia, Araçatuba-SP, Brasil

CEP: 16050-680

e-mail: leydsonf@fmva.unesp.br

Recebido: 11/03/11

Aprovado: 17/12/12

Auxílio à pesquisa (FAPESP, Proc. 2003/05724-5). 
anticorpos anti-Leishmania sp. foi realizada pela técnica de ELISA indireto de acordo com Lima et al. ${ }^{6}$, com algumas modificações. As amostras de soro foram diluídas 1:100 e utilizou-se conjugado anti-IgG de equino ligado à peroxidase (Bentyl, Montgomery, USA), na diluição de 1:20000 em PBS-T. Como controle positivo da reação foi utilizada uma amostra de soro de um equino parasitologicamente positivo com elevados títulos de IgG anti-Leishmania sp. e, como controle negativo o soro de um equino proveniente de área não endêmica para a doença. Os resultados foram expressos pela média da densidade óptica obtida dos soros em duplicata. A determinação do ponto de corte $(0,270)$ foi realizada com amostras de soro de 44 equinos residentes no município de São Sebastião do Paraíso, sul de Minas Gerais, área livre de leishmaniose tegumentar ou visceral. Amostras sororeagentes por ELISA foram testadas também por imunocromatografia utilizando-se Kit comercial (Kalazar Detect Animal Rapid $\mathrm{Test}^{\bullet}$ - Inbios International).

A maior parte das amostras de sangue foi coletada de animais utilizados para tração que permaneciam parte do tempo em áreas com grande quantidade de matéria orgânica, como lixões, onde havia substrato necessário para a multiplicação do vetor da leishmaniose. Os animais dormiam geralmente nos quintais das residências, próximos a cães. Quase todos possuíam manejo alimentar inadequado. Sessenta e oito animais $(14,59 \%)$ apresentaram resultados acima do ponto de corte da reação $(0,270)$ pela técnica de ELISA, com títulos variando entre 0,324 e 0,813. Destes, 19 foram considerados positivos pelo kit de imunocromatografia, correspondendo a $4,08 \%$ da população avaliada. O kit empregado utiliza um antígeno recombinante (rK39) e apresentou sensibilidade e especificidade de $86 \%$ e $91 \%$, respectivamente, em um estudo conduzido em cães ${ }^{7}$. Apesar de não ter sido ainda validado para o uso em equinos, por utilizar um antígeno recombinante sua especificidade tende a ser superior quando comparada ao uso de antígenos to- tais, que podem levar a reações cruzadas não somente com outras espécies da família Trypanosomatidae, mas também com organismos filogeneticamente distantes ${ }^{7}$.

A soroprevalência obtida por ELISA foi inferior a observada por Mukhtar et al. ${ }^{2}$, os quais verificaram a presença de anticorpos anti-L. donovani em $69 \%$ dos 96 muares avaliados em área endêmica para leishmaniose visceral no Sudão. Por outro lado, foi próxima a $12 \%$, soroprevalência observada em cães, no mesmo município ${ }^{1}$ e a $11,5 \%$, observada em um estudo realizado com gatos residentes na mesma área ${ }^{8}$. Levando-se em consideração a possibilidade de reações cruzadas com outros agentes etiológicos por meio da técnica de ELISA, se forem apreciados apenas os resultados da imunocromatografia, a soroprevalência na população estudada passa a ser inferior à observada em outras espécies animais no mesmo município. Apesar da evidência de que os equinos são capazes de se infectar com leishmanias, o papel desta espécie na transmissão das leishmanioses, quer como fonte de alimentação para os vetores ou como participante do ciclo epidemiológico da doença, ainda não está esclarecido $^{9,10}$. Alguns animais sororeagentes apresentaram títulos até três vezes $(0,813)$ acima do ponto de corte da reação $(0,270)$, apesar de estudos pretéritos sugerirem que a resposta imune humoral dos equinos 'a L. infantum é fraca quando comparada a resposta de cães ${ }^{11}$. Em cães, títulos de duas a quatro vezes acima do ponto de corte são considerados elevados e confirmam uma infecção ${ }^{12}$. Em contraste, a imunidade celular parece ser efetiva nos equinos, o que justifica a ausência de sintomas na maioria dos animais ${ }^{11}$.

Embora os cavalos do presente estudo sejam provenientes de área endêmica para leishmaniose visceral, não é possível excluir a possibilidade de contato com outra espécie de Leishmania, pois foram identificados cães infectados por Leishmania (Leishmania) amazonensis no mesmo município, cujo diagnóstico inicial era de leishmaniose visceral canina ${ }^{13}$. Os resultados ob- 
tidos no presente estudo não permitem afirmar que os equinos possuem algum papel na cadeia epidemiológica da leishmaniose visceral. Entretanto, eles indicam que esta espécie animal está em contato e deve atrair flebotomíneos transmissores da doença, uma vez que

\section{References}

1. CAMARGO-NEVES, V. L. F. A leishmaniose visceral Americana no Estado de São Paulo: situação atual. Boletim Epidemiológico Paulista, v. 1, p. 1-4, 2004.

2.MUKHTAR, M. M.; SHARIEF, A. H.; EL SAFFI, S. H.; HARITH, A. E.; HIGAZZI, T. B.; ADAM, A. M.; ABDALLA, H. S. Detection of antibodies to Leishmania donovani in animals in a kala-azar endemic region in eastern Sudan: a preliminary report. Transactions of the Royal Society Tropical Medicine and Hygiene, v. 94, p. 33-36, 2000.

3. KOEHLER, K.; STECHELE, M.; HETZEL, U.; DOMINGO, M.; SCHONIAN, G.; ZAHNER, H.; BURKHARDT, E. Cutaneous leishmaniosis in a horse in southern Germany caused by Leishmania infantum. Veterinary Parasitology, v. 109, p. 9-17, 2002.

4. SOLANO-GÁLLEGO, L.; FERNANDEZ-BELLON, H.; SERRA, R.; GALLEGO, M.; RAMIS, A.; FONDEVILA, D; FERRER, L. Cutaneous leishmaniosis in three horses in Spain. Equine Veterinary Journal, v. 35, p. 320-323, 2003.

5. ROLÃO, N.; MARTINS, M. J.; JOÃO, A.; CAMPINO, L. Equine infection with Leishmania in Portugal. Parasite, v. 12, p. 183-186, 2005.

6. LIMA, V. M. F.; GONÇALVES, M. E.; IKEDA, F. A.; LUVIZOTTO, M. C. R.; FEITOSA, M. M. Anti-leishmania antibodies in cerebrospinal fluid from dogs with visceral leishmaniasos. Brazilian Journal of Medical and Biological Research, v. 36, n. 4, p. 485-489, 2003.

7.ZANETTE, M. F. Comparação entre os métodos de ELISA, imunofluorescência indireta e imunocromatografia para o diagnóstico da leishmaniose visceral canina. 2006. $92 \mathrm{f}$. Dissertação (Mestrado em Ciência Animal) - Faculdade de Odontologia, Curso de Medicina Veterinária, Universidade Estadual Paulista, Araçatuba, 2006.

8. COSTA, T. A. C.; ROSSI, C. N.; LAURENTI, M. D.; GOMES, desenvolveram anticorpos séricos contra o parasita. Desta forma, é evidente a necessidade de investigação mais acurada sobre o real papel dos equinos residentes em áreas endêmicas na epidemiologia da doença, de forma a auxiliar em suas medidas de controle.

A. A. D.; VIDES, J. P.; SOBRINHO, L. S. V.; MARCONDES, M. Ocorrência de leishmaniose em gatos de área endêmica para leishmaniose visceral. Brazilian Journal of Veterinary Research and Animal Science, v. 47, n. 3, p. 213-217, 2010.

9. AGUILLAR, C. M.; RANGEL, E. F.; GARCIA, L.; FERNANDEZ, E.; MOMEN, H.; GRIMALDI, G. F.; VARGAS, Z. Zoonotic cutaneous leishmaniasis due to Leishmania (Viannia) braziliensis associated with domestic animals in Venezuela and Brazil. Memórias do Instituto Oswaldo Cruz, v. 84 , n. 1, p. 19-28, 1989.

10.KOUAM, M. K.; DIAKOU, A.; KANZOURA, V.; PAPADOPOULOS, E.; GAJADHAR, A. A.; THEODOROPOULOS, G. A seroepidemiological study of exposure to Toxoplasma, Leishmania, Echinococcus and Trichinella in equids in Greece and analysis of risk factors. Veterinary Parasitology, v. 170, n. 1/2, p. 170-175, 2010.

11.FERNÁNDEZ-BELLON, H.; SOLANO-GALLEGO L.; BARDAGÍ, M.; ALBEROLA, J.; RAMIS, A.; FERRER, L. Immune response to Leishmania infantum in healthy horses in Spain. Veterinary Parasitology, v. 135, n. 2, p. 181-185, 2006.

12.PALTRINIERI, S.; SOLANO-GALLEGO, L.; FONDATI, A.; LUBAS, G.; GRADONI, L.; CASTAGNARO, M.; CROTTI, A.; MAROLI, M.; OLIVA, G.; ROURA, X.; ZATELLI, A.; ZINI, E. Guidelines for diagnosis and clinical classification of leishmaniasis in dogs. Journal of the American Veterinary Medical Association, v. 236, n. 11, p. 1184-1191, 2010.

13.TOLEZANO, J. E.; ULIANA, S. R. B.; TANIGUCHI, H. H.; ARAÚJO, M. F. L.; BARBOSA, J. A. R.; BARBOSA. J. E. R.; FLOETER-WINTER, L. M.; SHAW, J. J. The first records of Leishmania (Leishmania) amazonensis in dogs (Canis familiaris) diagnosed clinically as having canine visceral leishmaniasis from Araçatuba County, São Paulo State, Brazil. Veterinary Parasitology, v. 149, n. 3/4, p. $280-284,2007$. 